\title{
ELECTROCARDIOGRAPHIC CHANGES FOLLOWING REPEATED \\ INJECTIONS OF DECAMETHONIUM AND SUBSEQUENT INJECTIONS OF SUCCINYLCHOLINE
}

\author{
R. T. Williams, M.R.C.S., L.R.C.P., AND E. A. Gain, M.D.*
}

SinCE Barlow and Ing ${ }^{1}$ and Paton and Zaimis ${ }^{2}$ described the neuromuscular blocking properties of decamethonium numerous reports have been published on the cardiovascular effects of decamethonium. The majority of reports favour the view that there are no appreciable changes in the pulse rate, rhythm, or blood pressure. $^{3-7}$ Other reports noted changes such as bradycardia, tachycardia, and fall of blood pressure.$^{8,9}$ Some of these changes were attributed to carbon dioxide retention due to inadequate ventilation. ${ }^{8}$ Guerrier and Mason ${ }^{9}$ reported the case of a thin male aged 48 anaesthetized for the removal of a ureteric calculus who, after the second injection of $2 \mathrm{mg}$. decamethonium, developed a pulse rate of $50 / \mathrm{min}$. from the original $80 / \mathrm{min}$., accompanied by a blood pressure fall. They reported two other similar cases, which they effectively treated with $15 \mathrm{mg}$. methylamphetamine intravenously. Foldes and Machaj ${ }^{5}$ reported their experiences with intermittent injections of decamethonium in 204 patients anaesthetized with thiopentone, nitrous oxide, oxygen, decamethonium. They stated "perhaps the most gratifying experience with syncurine was the lack of undesirable circulatory effects incidental to its use when adequate respiratory exchange was maintained. For practical purposes the blood pressure and pulse rate remained unchanged in most of the patients. No alarming hypotension or hypertension was seen in any of our cases."

The effect of intermittent injections of succinylcholine on the cardiovascular system was first described by $\mathrm{H}$. V. Martin. J. Bullough was invited to comment on his paper and later in the British Medical Journal (10) he wrote that a period of severe bradycardia occurred after the second or third injections of succinylcholine. Lupprian and Churchill-Davidson ${ }^{11}$ reported a series of cases given intermittent succinylcholine under thiopentone - nitrous oxide - oxygen anaesthesia in which they showed a severe bradycardia on the second and subsequent injections of succinylcholine in 39 out of 41 patients, and the following E.C.G. changes: sinus arrhythmias, variation of the $\mathrm{P}$ waves, wide Q.R.S. followed by an inverted $\mathrm{P}$ wave, ventricular extrasystoles, coupled beats, Wenckebach phenomenon, and ventricular standstill. These changes all occurred prior to surgical stimulation.

\section{Purpose}

Decamethonium and. succinylcholine are similar in pharmacological effects, in that they are both depolarizing neuromuscular blocking agents, and in chemical structure, in that they are both aliphatic compounds with one quaternary

*Department of Anaesthesia, University of Alberta Hospital, Edmonton, Alberta. 
ammonium group on each end of the chain. It should be noted, however, that the subtraction of four methylene groups from the decamethonium produces hexamethonium, a drug which is a ganglion blocking agent.

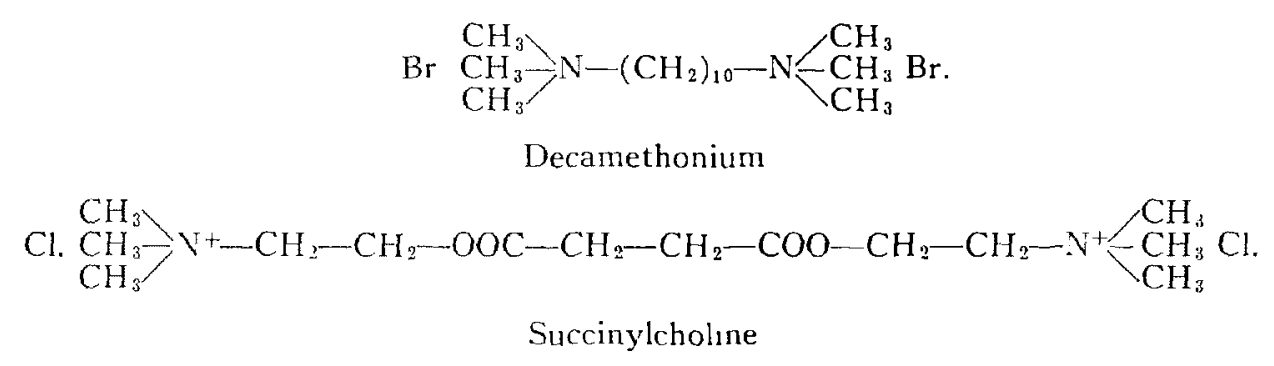

It was decided to attempt to correlate the cardiovascular effects of these two neuromuscular depolarizing drugs. Decamethonium alone is still used in some hospitals for intubation purposes, but it does not give such good relaxation of the vocal cords as succinylcholine. It is also used mixed with succinylcholine to allow time for anaesthesia to become fully established before full muscle tone returns. Decamethonium is still sometimes used as the only muscle relaxant during abdominal surgery. "The principal reason for the fall from grace of decamethonium is that there is no suitable antidote for it." 12

This series was conducted to determine two factors: (1) Whether intermittent decamethonium on the second or third injection would produce a bradycardia or an arrhythmia similar to that produced by intermittent succinylcholine. (2) Whether a bradycardia or an arrhythmia occurred on injection of succinylcholine following the decamethonium.

\section{Method}

The patients were selected at random, but they were all adults and assessed as status 1 for anaesthesia. They were premedicated with morphine or meperidine and atropine or hyoscine. They were all scheduled for relatively minor procedures and the majority consisted of patients operated on for varicose veins, herniae, or minor orthopaedic procedures. Anaesthesia for all patients was induced with 2 per cent thiopentone and maintained with nitrous oxide and oxygen $(6: 2$ litres $/ \mathrm{min}$.) in a semiclosed circuit with an absorber in the circuit. Manual hyperventilation was carried out throughout the procedure. Meperidine was given intermittently if required. Following induction, $4 \mathrm{mg}$. of decamethonium was injected. This was followed in 10 minutes by $3 \mathrm{mg}$. and in another 10 minutes by a further $3 \mathrm{mg}$. It was felt that decamethonium in excess of $10 \mathrm{mg}$. would be undesirable if one wished to avoid the possibility of a dual block. Hunter ${ }^{13}$ advised a total maximum dose of $10 \mathrm{mg}$.

Ten minutes after the last injection of decamethonium 40 or $50 \mathrm{mg}$. of succinylcholine was given, followed in 5 minutes by a further $50 \mathrm{mg}$. After each injection of relaxant an E.C.G. recording was taken. It was attempted to use lead II in each case, but on occasions this was impossible because of the site of the operation and another lead was used.

It was felt that a more natural state of affairs would exist if the recordings 


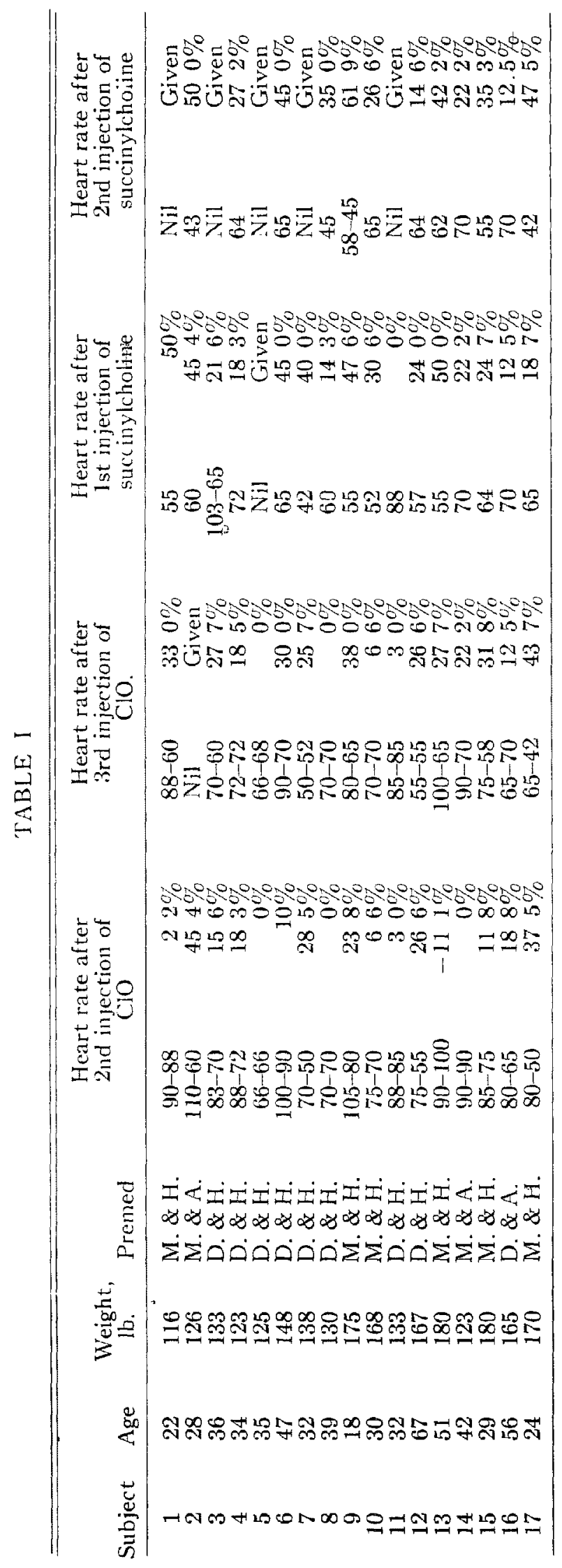


were taken during the surgical procedure as opposed to the method of Lupprian and Churchill-Davidson, who gave intermittent succinylcholine prior to surgical stimulation; usual premedication was also used for the same reason.

\section{Results (TABle I)}

In this series a 15 per cent decrease in the heart rate after each injection of relaxant was regarded as a significant slowing.

Following the second injection of decamethonium 8 (i.e., $2,3,4,7,9,12,16,17$ ) out of 17 patients developed a slowing of the heart rate and one patient exhibited an increase in heart rate; of the nine patients who did not develop a significant slowing after the second injection of decamethonium, 5 patients (i.e., 1, 6, 13, $14,15)$ developed a decrease in heart rate after the administration of the third injection of decamethonium. Therefore, during the administration of decamethonium at one stage or another the heart rate slowed by 15 per cent in 13 of. 17 patients.

Four patients (i.e., 5, 8, 10,11) did not develop a significant slowing following either the second or the third injection of decamethonium; two of these, however produced abnormal E.C.G. patterns.

The pulse rates to the nearest 10 after the last injection of decamethonium were:

$\begin{array}{lll}\text { No. of patients } & 1 & 40 / \mathrm{min} \\ & 2 & 50 / \mathrm{min} \\ 6 & 60 / \mathrm{min} \\ & 7 & 70 / \mathrm{min} \\ & 1 & 80 / \mathrm{min}\end{array}$

Succinylcholine was given to 16 patients following the decamethonium, 5 ( 1,3 , $6,10,13)$ of whom showed a significant slowing. Of these 5 , four had shown a slowing with decamethonium. The pulse rates after the first injection of succinylcholine were:

$\begin{array}{lll}\text { No. of patients } & 1 & 40 / \mathrm{min} . \\ & 4 & 50 / \mathrm{min} . \\ 7 & 60 / \mathrm{min} . \\ 3 & 70 / \mathrm{min} . \\ & 1 & 80 / \mathrm{min} .\end{array}$

Twelve patients were given a second injection of succinylcholine and two $(8,17)$ of these patients showed a significant slowing. The pulse rates after the second injection of succinylcholine were:

$\begin{array}{lll}\text { No. of patients } & 4 & 40 / \mathrm{min} . \\ & 1 & 50 / \mathrm{min} . \\ & 5 & 60 / \mathrm{min} . \\ & 2 & 70 / \mathrm{min} .\end{array}$

In the four cases in which atropine $0.6 \mathrm{mg}$. was given intravenously at the end of the procedure the heart rate and rhythm were restored to normal. 


\section{E.C.G. ABNORMALITIES}

Case 1: (a) Sinus rhythm (Fig. 1). (b) P.R: interval shortens and then is lost in the Q.R.S. complex. Wandering pacemaker after the third injection of decamethonium (Fig. 2). (c) Reverts to sinus rhythm. (Fig. 3). (d) Nodal rhythm appears with retrograde $\mathrm{P}$ waves after last injection of decamethonium (Fig. 4). (e)
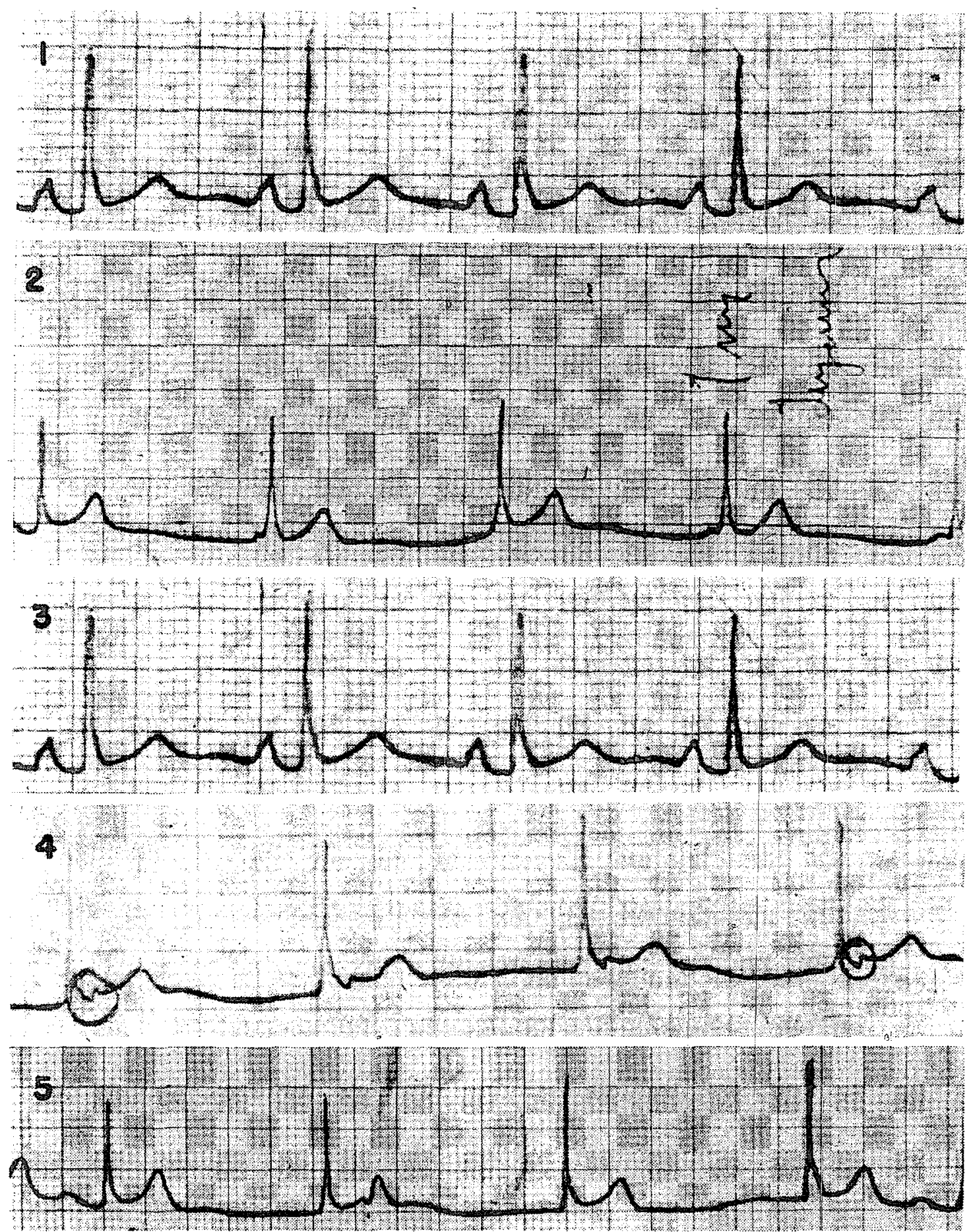

FigUres 1 to 5 
Wandering ectopic pacemaker persists following first injection of succinylcholine (Fig. 5). ( $f$ ) Atropine effective.

Case 2. (a) Ventricular ectopic beats with subsequent slowing after decamethonium. (b) After succinylcholine P.R interval lengthens and then shortens and later is incorporated in the Q.R.S. complex. T wave becomes flat. $(c)$ Atropine effective.

Case 5: (a) Sinus rhythm at 66/min. after $3 \mathrm{mg}$. decamethonium (Fig. 6). (b) Nodal rhythm with each nodal beat being followed by a ventricular extrasystole (ventricular bigemıni1) after second injection of decamethonium. Later reverts to sinus rhythm (Fig. 7).

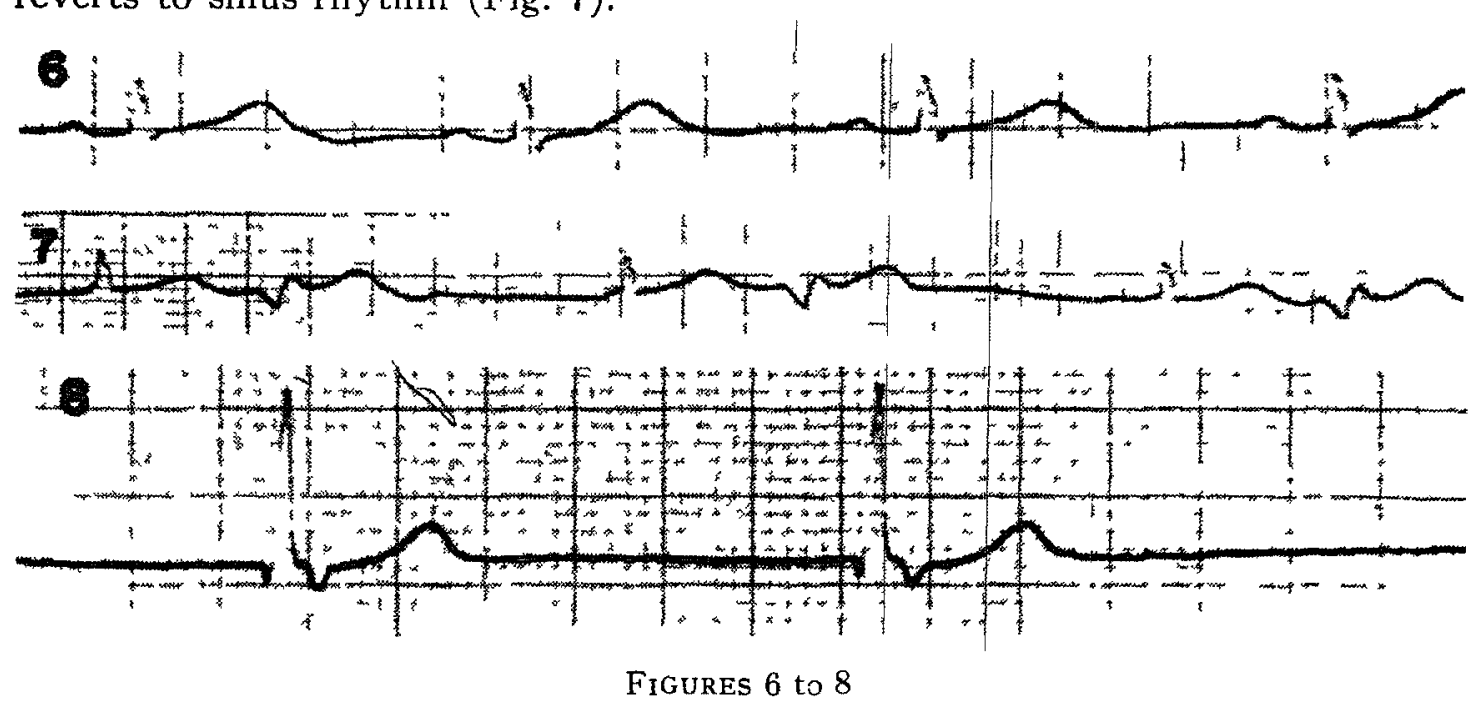

Case 8: (a) Slow nodal rhythm with a retrograde $\mathrm{P}$ wave following second injection of succinylcholine (F1g. 8).

Case 11 (a) Two episodes of sinus arrest following decamethonium second and third injection. (b) Atropme effective

Case 12: (a) One nodal premature beat following second injection of succiny 1choline.

\section{INTERPRETATION}

Although this series is small it appears that a slowing of the heart rate does occur with either the second or third injection of decamethonium, the slowing, however, is not quite as dramatic as has been reported with intermittent injections of succinylcholine. It is impossible to predict which patient will develop an arrhythmia.

Williams et al. ${ }^{14}$ described a series of five cases anaesthetized with cy clopropane in which succinylcholine was given following decamethonium. Four of the five patients showed a reduction in heart rate ranging from 3 to 28 per minute. They also reported that positive airway pressure did not affect the bradycardia.

It seems from these results that decamethonium reproduces to a milder degree the action of the initial sensitizing dose of succinylcholine. It is possible that the bradycardia occurring on successive doses of succinylcholine is due to the quarternary ammonium groups on either side of the alıphatic chain. The similarity of 
these two muscle relaxants to acetylcholine in chemical structure should not be ignored, but the reason that the cardiovascular effects do not occur on the first injection still remains a mystery. It is heartening to recall that to date no cardiac arrest has been reported that could be attributed directly to the cardiovascular effects of deçamethonium or succinylcholine. It is comforting also to know, however, that atropine given intravenously returns the rhythm to normal.

\section{SUMMARY}

Seventeen patients were given repeated injections of decamethonium up to a maximum of $10 \mathrm{mg}$. Fifteen patients showed E.C.G. changes or a significant bradycardia after either the second or the third injection. Sixteen patients were given succinylcholine following the decamethonium, five of whom developed a significant bradycardia. The similarity in chemical structure of these two muscle relaxants to acetylcholine is mentioned.

\section{ACKNOWLEDGMENT}

The authors wish to acknowledge with thanks the assistance of Dr. W. D. Macaulay (Fellow in Cardiology) for the E.C.G. interpretations.

\section{REFERENCES}

1. BARLow, R. B., \& ING, H. R. Curare like Action of Polymethylene Bisquarternary Ammonium Salts. Brit. J. Pharmacol. 3: 298 (1948).

2. Paton, W. D. M., \& Zaimis, E. J. The Pharmacological Action of Polymethylene Bistrimethyl Ammonium Salts. Brit. J. Pharmacol. 4: 381 (1949)

3. Hewer, A. J. H. et al. ClO as a Muscle Relaxant. Lancet 1: 817 (1949).

4. Enderby, G. E. Hale. Muscle Relaxation with Decamethonium. Anaesthesia 14: 138 (1959).

5. Foldes, F. F., \& MACHAJ, T. S. Syncurine, Its Use with Pentothal Sodium and Nitrous Oxide-Oxygen Anaesthesia in Abdominal Surgery. Anaesthesiology 12: 366 (1951).

6. Harris, L. C., \& Dripps, R. D. The Use of Decamethonium for the Production of Muscular Relaxation. Anaesthesiology 11: 215 (1950).

7. Colon-Yordan, E. et al. An Evaluation of the Use of Thiopental and Decamethonium Bromide for Rapid Endotracheal Intubation. Anaesthesiology 14: 255 (1953).

8. Holday, D. A. et al. Use of Bistrimethylammonium Decane Dibromide in Anaesthesia. New England J. Med. 241: 816 (1949).

9. Guerrier \& Mason, J. C. Undesirable Side Effects of Decamethonium Iodide. Brit. Med. J. $1: 1329(1952)$.

10. Bullough, J. Intermittent Suxamethonium Injections. Brit. Med. J. 1: 786 (1959).

11. Lupprian, K. G., \& Churchill-Davidson. Effect of Suxamethonium on Cardiac Rhythm. Brit. Med. J. 2: 1774 (1960).

12. Lawson, J. I. M.' Decamethonium a Reappraisal. Brit. J. Anaesth. $80: 240$ (1958),

13. Hunter, A. R. . Decamethonium and Hexamethonium. Brit. J. Anaesth. 2Q: 218 (1950).

14. Wirliams, C. H. et al. Effects of Intravenously Administered Succinylcholine on Cardiac Ráte, Rhythm and Arterial Blood Pressure in Anaesthetized Man. Anaesthesiology 2Q: 947. (1961). 